\title{
Ressignificação da Função Socioambiental da Propriedade como Direito Difuso: Multititularidade e Cidadania Pós-COVID-19
}

\section{Resignification of the Socio-Environmental function of Property as a Diffuse Right: Multi-Ownership and Post-COVID-19}

Lucas Souza Lehfeld ${ }^{1}$

Danilo Henrique Nunes ${ }^{2}$

Jonatas Santos Silva ${ }^{3}$

\section{RESUMO}

O estudo objetiva o entendimento da Multipropriedade e da Multitularidade como fenômenos sociais transformadores do conceito de propriedade até então existente. Aos conceitos privatistas de propriedade se aplicam as contemporâneas definições de economia do acesso e economia do compartilhamento, dando à propriedade - antes exclusivista - caráter inclusivo, ampliativo e de bem difuso, de uso comum. Sob o método hipotético-dedutivo e de revisão de literatura, pode-se compreender que, não bastasse relevante, o tema ainda será objeto de amplo debate na academia, possibilitando a inclusão de indivíduos alijados do direito à propriedade. Como principais resultados destaca-se que a economia do acesso se constitui em modelo de vida irreversível e transformador da sociedade com impacto significativo ao acesso dos indivíduos aos bens moveis e imóveis, materiais e imateriais, corpóreos e incorpóreos, promovendo a cidadania e o bem da coletividade.

\section{PALAVRAS-CHAVE:}

Propriedade; Ressignificação; Multitularidade.

\begin{abstract}
The study aims to understand Multipropriety and Multitularity as social phenomena that transform the concept of property that existed until then. Contemporary definitions of economics of access and economics of sharing apply to privatist concepts of property, giving property - formerly exclusivist, inclusive, expansive and of a diffuse nature, in common use. Under the hypothetical-deductive method and literature review, it can be understood that, if it were not relevant enough, the topic will still be the subject of a wide debate in the academy,

\footnotetext{
1 Pós-doutor em Direito. Doutor em Direito pela PUC/SP. Professor orientador dos programas de Doutorado e Mestrado em Direitos Coletivos e Cidadania na Universidade de Ribeirão Preto - Unaerp.

2 Doutorando e Mestre em Direitos Coletivos e Cidadania na Universidade de Ribeirão Preto - Unaerp. Professor Universitário e advogado.

3 Mestrando em Direitos Coletivos e Cidadania na Universidade de Ribeirão Preto - Unaerp. Professor Universitário e advogado. Universidade de Ribeirão Preto.
} 
allowing the inclusion of individuals excluded from the right to property. As main results, it is highlighted that the access economy constitutes an irreversible and transforming model of life for society with a significant impact on individuals' access to movable and immovable, material and immaterial, tangible and intangible assets, promoting citizenship and the good of collectivity.

\section{KEYWORDS:}

Property; Resignification; Time sharing.

\section{INTRODUÇÃO}

O instituto das multitularidades proporciona ao ambiente jurídico um novo horizonte, além da função social da propriedade, visto que atualmente estabelece e mantém uma verdadeira função socioambiental da propriedade na era do compartilhamento, pertencimento e inclusão.

A primeira situação (da qual pode-se denominar cláusula geral) constrange o titular do direito ao adimplemento de obrigações ante a coletividade. Impõe nesta situação a conciliação do desejável retorno individual/privado a um proveito social/comum. Na segunda situação, o avanço se dá nas múltiplas titularidades. Neste caso, há um maior progresso quanto a função exercida pela primeira cláusula geral e por respectiva razão, promove uma expansão dos direitos difusos. Justamente neste segmento (dos direitos difusos), a propriedade privativa e excludente é substituída por uma titularidade acessível, que promove a inclusão, seja ela econômica ou compartilhada. Deste modo, passa-se a conviver com a titularidade autônoma, que pertence e abrange a coletividade e demonstra ser socialmente mais justa.

Quanto aos bens comuns (cita-se como exemplo o Meio ambiente, patrimônio histórico, cultural e artístico), é necessário eliminar o atributo da exclusividade, pois é atributo dessa nova forma de pertencimento, a concessão de acesso e compartilhamento simultâneo de bens/serviços concomitantemente, e que estão suscetíveis a valoração econômica utilidade, gozo e disponibilidade, de modo evidente) e social (indisponíveis ao mercado posto que atrelados à cidadania, promovem a inclusão). 
Com respaldo na Constituição Federal da República do Brasil de 1988, doravante chamada $\mathrm{CRFB} / 88^{4}$ - que estabelece a função social e econômica da propriedade como direito fundamental e econômico, nos termos dos artigos $5^{\circ}$, caput, incisos XXII e XXIII; artigo 170, caput, incisos II e III; e, 182 e 186, incisos I a IV - questionar acerca da evolução e também do exercício das faculdades pelos multiproprietários.

Necessário apontar que, com base na interpretação sistemática dos dispositivos supramencionados, o melhor entendimento que se extrai é da CRFB/1998, pois esta estabelece dupla previsão do direito de propriedade, que consegue atender a objetivos diferentes, porém, convergentes na sociedade contemporânea. Na concepção do direito individual, promove a proteção da propriedade como modalidade de realização pessoal (Direito à propriedade - artigo $5^{\circ}$, caput). Já sob a perspectiva socioeconômica, a propriedade serve de instrumento para a promoção do bem comum (Direito de propriedade - artigo $5^{\circ}$, inciso XXIII).

O modelo de propriedade contemporâneo proporciona uma tensão entre dois elementos, visto que há um certo conflito entre direito de propriedade (art. 5, XXII) e direito à propriedade (art. $5^{\circ}$, caput). Nesta ocasião, percebe-se que há a conglobação no direito de excluir daqueles que já têm e o direito a não ser excluído àqueles que anseiam "vir a ter". Nesse sentido, ao tratar da nova relação entre o mundo das pessoas e o mundo dos bens - há muito tempo substancialmente confiado à lógica do mercado- bem pontuou Stefano Rodotás:

\footnotetext{
Bens comuns são aqueles funcionais ao exercício de direitos fundamentais e ao livre desenvolvimento da personalidade, que devem ser salvaguardados, removendo-os da lógica destrutiva do curto prazo, projetando a sua tutela ao mundo mais distante, habitado pelas gerações futuras. $\mathrm{O}$ acoplamento aos direitos fundamentais é essencial e nos leva para além de uma referência genérica à pessoa. É um tema "constitucional", pelo menos para todos os que, voltando o olhar para o mundo, captam a insustentabilidade crescente das sistematizações cegamente confiadas à lei "natural" dos mercados".
}

O mesmo se diga da trajetória percorrida pelo instituto propriedade. É possível perceber que a linguagem clássica e atual civilista não possuem os requisitos para albergar os conceitos de multititularidade, acesso, compartilhamento e de pertencimento inclusivo.

\footnotetext{
4 BRASIL. Constituição da República Federativa do Brasil de 1988. Disponível em: http://www.planalto.gov.br/ccivil_03/constituicao/constituicaocompilado.htm Acesso em: 30 abr. 2020.

${ }^{5}$ RODOTÁ, Stefano. Il terribile diritto. Studi sulla proprietà privata e i beni comuni. 3. ed. Bologna: Il Mulino, 2013, p. 464.
} 
No último capítulo do desenvolvimento abordar-se-á economia do compartilhamento após os efeitos causadas pela pandemia Covid-19, ao ponto que se pontuará tanto o sistema de trabalho e de mobilidade. Ademais, será observado que alguns atos praticados durante o Covid19 poderão ser utilizados beneficamente futuramente.

Imperioso pontuar que o objetivo geral deste artigo é investigar os bens comuns e direitos difusos - de modo especial, o meio ambiente - disponíveis à multititularidade que resgatam e consolidam a esfera social do indivíduo, ante a desmaterialização dos bens e da ascensão do modelo de compartilhamento. Também será analisado a necessária consolidação dos direitos difusos em nosso ordenamento jurídico, para a possível criação de uma lógica do pertencimento, capaz de refletir a funcionalização do direito de propriedade a serviço de seu viés mais humanista e inclusivo.

Com a presente configuração social, será possível articular soluções que resolveram o problema tachado como "tragédia dos comuns", através da relevante harmonização de diferentes estatutos proprietários em uma abrangente noção de patrimônio. Para que assim ocorra, é necessário reconhecer a diferente dimensão jurídica que supera a já superada dicotomia público-privado, além do individualismo proprietário e da tradicional gestão pública dos bens de uso comuns e essenciais.

\section{ASPECTOS JURÍDICOS CONTEXTUALIZATÓRIOS}

O estudo da multititularidade pressupõe a compreensão do direito de propriedade por um viés diverso daquele que serviu de pano de fundo à tutela conferida ao instituto pelas grandes codificações ocidentais, especialmente às civilistas restritivas, visando apenas o prisma patrimonial. Assim, distante da ideia de exclusividade como pressuposto indispensável, a proteção dos bens comuns, incluindo-se aqui o Meio ambiente, encontram respaldo no viés de acesso, pertencimento, economia e compartilhamento dado o caráter instrumental ostentado por tais bens: em virtude de sua relação indissociável com a efetivação dos direitos fundamentais, 
a sua eventual privação colocaria em risco a dignidade humana ${ }^{6}$, a própria vida e a concreção dos objetivos a serem perseguidos pela CRFB/88.

Em sede de tutela de bens comuns, há necessidade de se garantir o efetivo acesso a estes a tempo indeterminado por toda sociedade. Desta maneira, os direitos (que são constitucionalmente consagrados) conseguirão ser efetivamente concretizados e assegurados a $\operatorname{todos}^{7}$. Neste caso haverá a inclusão. Em modo contraditório, imperioso se torna a observação da existência instrumental que promove a proteção de bens comuns. Caso esteja consumado o risco de escassez a este bem, o acesso ao mesmo e garantia de direitos já positivados se tornarão inviáveis ${ }^{8}$.

Importante pontuar que a presente pesquisa tem como pretensão expandir além da propriedade codificada. Neste caso será abordado as relações de pertencimento e os eventuais novos objetos de acesso e compartilhamento. Ainda pretende-se destacar o conceito de propriedade proposto no império romano (que vinculava à família e ao Estado) e posteriormente o individualismo proprietário, que foi desenvolvido no cenário burguês, que acarretaram diretamente "ao direito de acesso e multipropriedade como nova e predominante expressão do pertencimento" 9 .

Menciona-se que uns dos maiores obstáculos a serem enfrentados é a efetivação dos bens comuns (caracterizados como direitos difusos), visto a seu conteúdo demasiadamente principiológico. É justamente o contrário dos demais direitos insertos nos textos originalmente codificados. Em função disto, existe a possibilidade de ser amplamente discutido e explorado

\footnotetext{
${ }^{6}$ Sobre a dignidade da pessoa humana, Sarlet leciona que "justamente considerando o elo entre direitos fundamentais sociais, vida e dignidade da pessoa humana, que, ademais, dizem com necessidades existenciais de todo e qualquer indivíduo, que, na sequência, se estará a examinar o assim designado mínimo existencial e sua relação com os direitos sociais, com destaque para a evolução no âmbito do direito constitucional alemão, especialmente considerando a recente decisão do Tribunal Constitucional Federal (Bundesverfassungsgericht) sobre o tema e a sua conexão com a problemática da democracia e dos limites ao legislador". SARLET, Ingo Wolfgang. Dignidade da pessoa humana e direitos fundamentais na Constituição Federal de 1988. 8. ed. Porto Alegre: Livraria do Advogado, 2010, p. 238.

${ }^{7}$ MAIA, Roberta Mauro Medina. Resenha à obra a tutela das multititularidades: Repensando os limites do direito de propriedade, de Everilda Brandão Guilhermino. Revista Brasileira Direito Civil, v. 18, p. 245-248, out./dez. 2018, p. 246. Disponível em:

<https://heinonline.org/HOL/LandingPage?handle=hein.journals/rvbsdirec18\&div=14\&id=\&page=>. Acesso em: 29 maio. 2020.

${ }^{8}$ Ibid., p. 246.

${ }^{9}$ Ibid., p. 247.
} 
pelos seus titulares. Entretanto, necessário se faz a conceituação de direitos difusos no presente trabalho, ainda que amplamente discutido Kazuo Watanabe a faz:

Os termos "interesses" e "direitos" foram utilizados como sinônimos, certo é que, a partir do momento em que passam a ser amparados pelo direito, os "interesses' assumem status de "direitos", desaparecendo qualquer razão prática, e mesmo teórica, para a busca de uma diferenciação ontológica entres eles ${ }^{10}$.

Hugo Nigro Mazilli completa a conceituação, pontuando que os direitos difusos são "como um feixe ou um conjunto de interesses individuais, de objeto indivisível, compartilhados por pessoas indetermináveis, que se encontram unidas por circunstâncias de fato conexas"11.

Todo o contexto conduz ao questionamento seguinte, que enseja a problemática da pesquisa: os bens comuns e direitos difusos - a exemplo do Meio ambiente - disponíveis à multititularidade que resgatam e consolidam a esfera social do indivíduo, ante a desmaterialização dos bens e da ascensão do modelo de compartilhamento, bem como da necessária consolidação dos direitos difusos em nosso ordenamento jurídico, são passíveis de criação de uma lógica do pertencimento, capaz de refletir a funcionalização do direito de propriedade e o viés mais humanista a ela atrelado?

Na tentativa provisória de dar uma resposta ao problema, o que se observa é que, à primeira vista, a proteção constitucional e infraconstitucional dada aos bens de uso comuns, especialmente à multititularidade, carece de maior proteção jurídica. Assim, é insatisfatória a tutela dos direitos difusos, inicialmente proposta pela CRFB/88, sendo cabível enxergar a dupla titularidade sobre eles: uma difusa e outra individual, quase que obstruindo o exercício de direitos por parcela significativa da sociedade.

Neste momento deve-se fazer uma pergunta simples, mas de total importância: o que é o espaço e o tempo no tocante a Multipropriedade? Para isto, a melhor forma exemplificativa é ressaltada abaixo:

A laje e a multipropriedade confirmam a relatividade de ambos os conceitos no que se aplica à propriedade clássica. A laje por se constituir em fracionamento espacial da propriedade, desvinculada do solo alheio ou de uma fração ideal - uma titularidade em 3D (que não chega a ser um multiverso, pois existem relações jurídicas entre o proprietário e o lajeário). A multipropriedade, por sua vez, não desafia o espaço, mas

\footnotetext{
${ }^{10}$ Código Brasileiro de Defesa do Consumidor: Comentado pelos autores do anteprojeto. 9. ed. Rio de Janeiro: Forense, 2007, p. 815.

${ }^{11}$ A defesa dos interesses difusos em juízo: meio ambiente, consumidor, patrimônio cultural, patrimônio público e outros interesses, 29. ed. São Paulo: Saraiva, 2016, p. 50.
} 
o tempo. Nessa relação jurídica de aproveitamento econômico de bens - que ingressou no CC como modalidade especial de condomínio em propriedade imobiliária adentra-se a uma distinta dimensão da titularidade, na qual o pertencimento se exerce periodicamente sobre uma unidade temporal de uma fração ideal física. Afasta-se o fenômeno da composse, pois a fruição do direito se concebe alternada e sucessivamente. No aspecto funcional, enquanto a laje incorpora o fenômeno tipicamente brasileiro do "puxadinho", como acesso ao mínimo existencial, frequentemente o "time sharing" mira exatamente o oposto: o máximo existencial, pelo compartilhamento de titularidade de bens supérfluos como resorts de férias, aeronaves, iates e carros de luxo ${ }^{12}$.

Ante ao modelo auto-exemplificativo supradito, percebe-se que a economia do compartilhamento é um novo padrão colaborativo que não se identifica propriamente com o universo do direito das coisas, mas que nele impacta profundamente. Felson e Spaeth definem a economia do compartilhamento como:

[... ] expressões genéricas que abrangem vários significados, sendo frequentemente usadas para descrever atividades humanas voltadas à produção de valores de uso comum e que são baseadas em novas formas de organização do trabalho (mais horizontais que verticais), na mutualização dos bens, espaços e instrumentos (com ênfase no uso e não na posse), na organização dos cidadãos em redes ou comunidades, e que geralmente são intermediadas por plataformas Internet ${ }^{13}$.

$\mathrm{Na}$ esteira defendida por Rosenvald ${ }^{14}$, o conceito mercado não é mais traduzido pelo câmbio de propriedades. Nesta ocasião defende que futuramente, as novas gerações escolheram possuir acesso à fruição de bens, do que possuir algo individual, visto a burocracia para mantêlo. Percebe-se assim, que devido as imposições legais a propriedade, a tendência é que bens compartilhados substituam o modelo convencional. As consequências desta ação será a criação de uma rede de usuários que dispensam a titularidade dos bens e mitigação da ociosidade destes, através de acesso temporário.

Com esta alteração na sistemática em que são definidos a propriedade, é possível notar que com a ascensão do compartilhamento entre as pessoas, há uma consolidação e enraizamento dos direitos difusos no Brasil. Ante a esta consolidação, necessária se faz, através de estudos, a concretização e conscientização das normas que regulamentam o direito a propriedade a este novo segmento.

\footnotetext{
${ }^{12}$ ROSENVALD, Nelson. Cinco Conceitos que Ressignificam a Propriedade. Nelson Rosenvald. [s. 1], 04 jun. 2019. Disponível em: < https://www.nelsonrosenvald.info/single-post/2019/06/04/Cinco-Conceitos-queRessignificam-a-Propriedade>. Acesso em: 30 maio. 2020.

${ }^{13}$ Community structure and collaborative consumption: "A Routine Activity Approach". The American Behavioral Scientist, v. 21, n. 4, p. 614-624, 1978.

${ }^{14}$ Op. cit.
} 


\section{NOÇÕES JURÍDICAS CONTEMPORÂNEAS}

O fenômeno da Multipropriedade - embora recentemente incluído no ordenamento jurídico brasileiro por meio da Lei Federal no 13.777 de 20 de dezembro de $2018^{15}$, que altera as Leis 10.406, de 10 de janeiro de 2002 (Código Civil) e 6.015, de 31 de dezembro de 1973 (Lei dos Registros Públicos), para dispor sobre o regime jurídico da multipropriedade e seu registro - é instituto jurídico relevante no direito comparado.

Partindo do ponto de vista conceitual, Gustavo Tepedino, primeiro doutrinador brasileiro a estudar o tema, afirma que "multipropriedade pode ser definida como um parcelamento temporal do bem em unidades autônomas periódicas. É pulverizar um bem físico no tempo por meio de uma ficção jurídica"16. Assim, tem-se que, a multipropriedade é a consagração do parcelamento temporal do bem. Nesse sentido, Frederico Henrique Viegas de Lima, conceitua, ainda, que "Multiproprietário é o titular da unidade periódica" e completa:

\footnotetext{
A unidade periódica é a coisa física considerada apenas em uma fração de tempo do ano. O direito real de propriedade periódico é o vínculo jurídico entre o multiproprietário e a unidade periódica. Enfim, é o direito de propriedade sobre uma unidade periódica ${ }^{17}$.
}

De tal forma que, eventualmente pode ser considerada uma das melhores formas ou meios para que seja valorizada a função social da propriedade. A valorização da função social acaba por ampliar e modificar a conceituação a propriedade privada clássica, lhe atribuindo uma nova ressignificação de direito difuso, de bem comum, fluido e de uso de todos.

Recém-chegado ao direito brasileiro, o instituto da Multipropriedade nasce na Europa, com o intuito de melhorar o aproveitamento das propriedades em períodos de férias ${ }^{18}$. A realização de viagens internacionais impõe a necessidade de aquisição de imóveis abrangidos

\footnotetext{
${ }^{15}$ BRASIL. Lei federal $n^{\circ} 13.777$ de 20 de dezembro de 2018 . Altera as Leis $\mathbf{n}^{\circ}$ 10.406, de 10 de janeiro de 2002 (Código Civil), e 6.015, de 31 de dezembro de 1973 (Lei dos Registros Públicos), para dispor sobre o regime jurídico da multipropriedade e seu registro. Disponível em: http://www.planalto.gov.br/ccivil_03/_Ato2015-2018/2018/Lei/L13777.htm Acesso em: 02. Maio. 2020.

16 TEPEDINO, Gustavo. Multipropriedade imobiliária. Editora Saraiva, São Paulo: 1993, p. 01.

17 Aspectos teóricos da multipropriedade no direito brasileiro. Revista dos Tribunais, 658/40.Disponível em: <https://bdjur.tjdft.jus.br/xmlui/handle/tjdft/36335>. Acesso em: 07. jul. 2019.

${ }^{18}$ SARAIVA, Bruno de Sousa. Uma análise jurídica da multipropriedade imobiliária. THEMIS: Revista da Esmec, v. 9, 2011, pp. 95-113. Disponível em: < http://revistathemis.tjce.jus.br/index.php/THEMIS/article/view/104>. Acesso em: 01 jun. 2020.
} 
pela multipropriedade, que permite usufruir deste bem por um determinado período. Visto que o Brasil possuí paraísos turísticos em todas as suas regiões, surge finalmente a primeira lei brasileira sobre a multipropriedade, também chamada de time sharing ${ }^{19}$.

\title{
2.1 Dos conceitos clássicos e contemporâneos de propriedade
}

O instituto da Multipropriedade pode ser considerado a superação do conceito clássico civilista, patrimonialista, excludente e privatista da propriedade. Veja-se as palavras de Silvio de Salvo Venosa:

\begin{abstract}
Antes da época romana, nas sociedades primitivas, somente existiria propriedade para as coisas móveis, exclusivamente para objetos de uso pessoal, tais como peças de vestuário, utensílios de caça e pesca. O solo pertencia a toda coletividade, todos os membros da tribo, da família, não havendo o sentido de senhoria, de poder de determinada pessoa ${ }^{20}$.
\end{abstract}

Em função disso, surge os primeiros pensamentos de propriedade na forma individual (privada) e perpétua, a qual poderia ser repassada aos descendentes. Após essa fase, por volta do século XVIII, passou-se a postular leis que visavam proteger e conceituar o direito de propriedade $^{21}$. Segundo Vanessa Massaro “essa escola tem como ideologia a liberdade do indivíduo em praticar determinadas ações de acordo com o seu próprio entendimento e razão, assim, "usar o seu próprio poder a seu arbítrio para a conservação da sua natureza", 22 .

Em breve avanço histórico, especialmente após 1945, com o findar da 2a Grande Guerra, o instituto da propriedade recebeu uma funcionalização, em razão dos gigantescos movimentos que construíam. Com isto, houve uma "sobreposição da natureza função social sob a natureza de um direito subjetivo" 23 , que afetou inclusive o contexto brasileiro.

\footnotetext{
${ }^{19}$ SARTORI, Nathália de Almeida. Natureza Jurídica Da Multipropriedade. Trabalho de Conclusão de Curso. Centro Universitário de Brasília, UniCEUB, p. 28. Disponível em: < https://repositorio.uniceub.br/jspui/bitstream/235/11950/1/21395372.pdf>. Acesso em: 07. jul. 2019.

${ }^{20}$ Direito Civil: Direitos Reais. 4. ed. São Paulo: Atlas S/A, 2004, p. 169.

${ }^{21}$ Op. cit., p. 10.

${ }^{22}$ MASSARO, Vanessa. Reflexões sobre o jusnaturalismo: jus naturale, Web artigos. [s. 1], 06 set. 2014. Disponível em: <https://www.webartigos.com/artigos/reflexoes-sobre-o-jusnaturalismo-jus-naturale/124860/>. Acesso em: 07. jul. 2019.

${ }^{23}$ PAGANI, Elaine Adelina. $\mathrm{O}$ direito de propriedade e o direito à moradia: um diálogo comparativo entre $\mathrm{o}$ direito de propriedade urbana imóvel e o direito à moradia. Porto Alegre: EDICPUCRS, 2009, p. 42.
} 
Porém, é com a positivação da CRFB/1988, que a "função social se inclina em recepcionar o interesse público e ao cumprimento de deveres para com a sociedade, enquanto que o direito de propriedade busca uma satisfação de interesses particulares"24.

Deste modo, é possível analisar que a propriedade ao longo dos séculos é analisada, conceituada e protegida, sendo a nível particular ou coletivo. No território brasiliano encontra respaldo constituinte, ainda que tenha sido observada desde após o fim da Grande Guerra. Com isto, busca o Estado manter o direito de possuir a propriedade em si e o dever de promover a esta um cumprimento da função social, que passar a abranger toda a coletividade brasileira.

\section{DA MULTITITULARIDADE E DA RESSIGNIFICAÇÃO DA PROPRIEDADE COMO DIREITO DIFUSO}

Após ter realizado a conceituação de multipropriedade, necessário se faz a análise de ressignificação deste instituto ante ao direito difuso. Para isto, aponta-se que quando teve a oportunidade, Miguel Reale descreveu na exposição de motivos do Código Civil de 2002 (ainda que escrito em 1975) que o "sentido social do direito de propriedade deve inspirar as mais diversas normas, sendo um alto nível de alcance na inovação do ordenamento jurídico brasileiro, acarretando, também, uma nova conceituação da posse" 25 .

Ou seja, a lei tem o dever de proteger a posse da propriedade, para que esta atenda a sua função social e com isto, poder abranger tanto o sujeito individual, quanto a coletividade. Nesta perspectiva, pontua-se a passagem feita por Gustavo Tepedino, a qual afirma que a propriedade possui conexão com as relações jurídicas sociais:

\footnotetext{
A construção fundamental para a compensação das inúmeras modalidades contemporâneas da propriedade, serve de moldura para uma posterior elaboração doutrinária, que entrevê na propriedade não mais uma situação de poder, por si só e abstratamente considerada, o direito subjetivo por excelência, mas 'uma situazione giuridica típica e complessa', necessariamente em conflito ou coligada com outras, que encontra a sua legitimidade na concreta relação jurídica na qual se insere.
}

\footnotetext{
${ }^{24}$ DINIZ, Maria Helena. Direito Civil Brasileiro: Direito das Coisas. 17. ed. São Paulo: Saraiva, 2002, p. 101.

${ }^{25}$ REALE, Miguel apud SARTORI, Nathália de Almeida. Natureza Jurídica Da Multipropriedade. Trabalho de Conclusão de Curso. Centro Universitário de Brasília, UniCEUB, p. 28. Disponível em: < https://repositorio.uniceub.br/jspui/bitstream/235/11950/1/21395372.pdf>. Acesso em: 09 ago. 2019.
} 
Cuida-se da tese que altera, radicalmente, o entendimento tradicional que identifica na propriedade uma relação entre sujeito e objeto, característica típica da noção de direito real absoluto (ou pleno), expressão da 'massima signoria sulla cosa'formulação incompatível com a ideia de relação intersubjetiva.

A propriedade, portanto, não seria mais aquela atribuição de poder tendencialmente plena, cujos confins são definidos externamente, ou, de qualquer modo, em caráter predominantemente negativo, de tal modo que, até uma certa demarcação, o proprietário tenha espaço livre para as suas atividades e para a emanação de sua senhoria sobre o bem. A determinação do conteúdo da propriedade, ao contrário, dependerá de certos interesses extrapatrimoniais, aos quais vão ser regulados no âmbito da relação jurídica de propriedade ${ }^{26}$ ".

Ante ao que foi exposto, a propriedade garante um certo espaço no solo para que a privacidade e intimidade das pessoas sejam resguardadas, desde que lícitas. Além destes dois itens, fornece a seu proprietário um aconchego com maior segurança, que se desdobra em pessoal e patrimonial. Impedindo a violação destes itens básicos, a sociedade em si é beneficiada, pois garante a harmonia entre os seus indivíduos.

E é justamente neste ponto que, ao exercer o direito a propriedade, o proprietário fornece e concretiza o objetivo desta a comunidade. Neste momento, cumpre espírito da propriedade na CRFB/1988. Deste modo, a propriedade - ainda que privada - é considerada como um valor de cidadania, atendendo ao disposto no Art. $1^{\circ}$, incisos II e III da CRFB/1988, que tratam da Cidadania e da Dignidade da Pessoa Humana como princípios fundantes do Estado Democrático de Direito brasileiro.

\subsection{Da multitutilaridade como efetivação do Estado Socioambiental de Direito}

A expressão foi introduzida por Everilda Brandão Guilhermino em sua obra "A tutela das multititularidades". Denota a autora nesta ocasião que "as multitularidades abrem um novo horizonte nos direitos reais, para além da função social da propriedade" 27 .

Inicialmente, ressalta-se que é imposto ao particular (privado) aceitar as imposições feitas pela comunidade que convive, como reiteradamente dito, para que seja composto o desejo individual e coletivo. Feito isto, um passo as múltiplas titularidades surgirá, quando comparada

\footnotetext{
${ }^{26}$ TEPEDINO, Gustavo apud SARTORI, Nathália de Almeida. Natureza Jurídica Da Multipropriedade. Trabalho de Conclusão de Curso. Centro Universitário de Brasília, UniCEUB, p. 28. Disponível em: < https://repositorio.uniceub.br/jspui/bitstream/235/11950/1/21395372.pdf>. Acesso em: 07. jul. 2019.

27 GUILHERMINO, Everilda Brandão. A tutela das multititularidades: repensando os limites do direito de propriedade. Rio de Janeiro: Lumen Juris, 2018. p. 226.
} 
as funções sociais, em função de suprimir a propriedade exclusiva e individual a uma que pertence a sociedade ${ }^{28}$. É o que ocorre quanto aos bens comuns - principalmente quando relacionado ao Meio ambiente - pois há exclusão da exclusividade, visto que há necessidade de ser imposto o acesso simultâneo, pertencimento e compartilhamento dos bens em forma concomitante que sejam "suscetíveis de valoração econômica (quanto à sua disponibilidade) e social (indisponíveis ao mercado posto atrelados à cidadania)" ${ }^{29}$.

Assim, cinco conceitos ressignificam a propriedade, a saber, o primeiro, o de acesso, no qual a propriedade moderna é um direito fundamental individual de seu titular, a qual o se deve garantir e proteger contra o Estado e demais indivíduos que não são proprietários. Complementa-se o exposto conforme as palavras de Nelson Rosenvald:

Esta propriedade também é uma garantia institucional, representando o hígido funcionamento do mercado, traduzida a segurança jurídica na conservação da ordem econômica. A noção de "acesso" ingressa no Estado Democrático de Direito, pela qual o "rule of law" transcende a conservação daquilo que se "tem", incluindo a promoção de direitos fundamentais para os futuros proprietários ${ }^{30}$.

Já o conceito de pertencimento representa dizer que propriedade e domínio exprimem conceitos autônomos, mesmo que complementares ${ }^{31}$. Primeiramente, assevera-se que a propriedade por si só se constitui em uma situação complexa, visto que pode ser conceituada como o "direito que permite a um titular usar, gozar e dispor de certos bens, desde que ele o faça de modo a realizar a dignidade de pessoa humana" 32 , que como pontuado, deve ser aplicado de acordo com a sua função social, isto é, contribuir para a melhoria de condições da sociedade no todo, com intuito que esta se torne uma sociedade justa ${ }^{33}$.

Em contrapartida, o domínio pode ser caracterizado como o sustentáculo dos direitos reais, pois conforme dispõe a doutrina este instituto é caracterizado pelas "faculdades de gozar,

\footnotetext{
${ }^{28}$ ROSENVALD, Nelson. Cinco Conceitos que Ressignificam a Propriedade. Nelson Rosenvald. [s. 1], 04 jun. 2019. Disponível em: < https://www.nelsonrosenvald.info/single-post/2019/06/04/Cinco-Conceitos-queRessignificam-a-Propriedade>. Acesso em: 30 maio. 2020.

${ }^{29}$ Ibid.

${ }^{30}$ Ibid.

${ }^{31}$ ARONNE, Ricardo. Propriedade e Domínio A Teoria da Autonomia: Titularidades e Direitos Reais nos Fractais do Direito Civil-Constitucional. 2. ed. Porto Alegre: Livraria do Advogado Editora, 2014.

${ }^{32}$ GONDINHO, André Osório. Função social da propriedade. In: TEPEDINO, Gustavo (coord.). Problemas de direito civil constitucional. Rio de Janeiro: Renovar, 2000, p. 429.

${ }^{33}$ GOMES, Daniela Vasconcellos. A noção de propriedade no direito civil contemporâneo. Revista Ciência Jurídica, v. 140, 2008, p. 335-343.
} 
usar, dispor e reaver a coisa, são inerentes ao domínio" ${ }^{34}$. Pelo que parece, poderia ser caracterizado como um sinônimo de propriedade, porém, a respectiva situação não deveria ocorrer, haja vista que no domínio existe o poder imediato sobre a coisa. E justamente por se limitar a classificação clássica das faculdades de uso, gozo e disposição, o domínio é insubmisso compartilhamento, pois impõe a exclusividade.

A limitação clássica acima denotada deixa a desejar nos dias atuais, pois com a nova vertente do compartilhamento, que determina que a nova versão dos bens essenciais seja utilizada na gestão, ignorando desta feita o pertencimento, fica ultrapassada. Nos termos atuais, é garantido o acesso ao bem e sua previsão a participação de sujeitos interessados, mediante uma administração guiada pelo princípio da solidariedade, inserto no art. $3^{\circ}$, inciso I, da CRFB/1988.

Apontadas respectivas situações, incumbe apontar que a multipropriedade, possibilita o máximo existencial, pelo compartilhamento de titularidade de bens - antes, somente supérfluos como resorts de férias, aeronaves, iates e carros de luxo, agora, indispensáveis, como os bens de uso comum, dentre eles os espaços públicos e o meio ambiente. Por fim, a economia do compartilhamento, invés da posse, é novo padrão colaborativo pessoal, familiar e profissional que não se identifica propriamente com o universo do direito das coisas, mas que nele impacta profundamente.

\section{DA ECONOMIA DO COMPARTILHAMENTO PÓS-COVID-19}

Com o surgimento de um vírus até desconhecido (Covid-19), países e pessoas em esfera global foram obrigadas a remanejarem a sua vivência habitual e corriqueira, ante a eventual letalidade mortal causada pelo vírus supradito. Em função disto, locais públicos foram

\footnotetext{
${ }^{34}$ OLIVEIRA, Álvaro Borges de; BORDERES, Kenia Bernardes. Propriedade, domínio, titularidade, posse e detenção. Revista Jurídica - CCJ/FURB, v. 13, n 25, p. 99 - 107, jan./jul. 2009, p. 103. Disponível em: < https://bu.furb.br/ojs/index.php/juridica/article/view/1601/1072>. Acesso em: 08 jun. 2020.
} 
fechados, medidas de isolamentos sociais foram solicitadas e demais ações pelos entes estatais com intuito de manter a população em suas respectivas residências.

Certamente que, ainda que negativamente, a pandemia provocada pelo Corona vírus possibilita e até força diversas alterações no cotidiano, sejam elas impostas imediatamente ou em um futuro próximo. Essas alterações poderão afetar diretamente no dia-a-dia da sociedade mundial, tanto na forma em que vivem, quanto a forma que se expõem a fora de suas casas. Justamente por ser necessário a adoção de medidas e ações que antes sequer eram cogitadas, necessário se faz a análise dos impactos causado na economia compartilhada ${ }^{35}$, principalmente após o retorno gradual das atividades que anteriormente eram executadas sem maiores preocupações médicas.

As consequências podem ser causadas justamente pela desconfiança das pessoas em utilizarem bens ou serviços que em momentos antes foram utilizados por outras pessoas que sequer conheciam e por tal razão, não sabem por onde andaram ou com quais outras pessoas mantiveram contato, é o caso do Airbnb e Uber ${ }^{36}$.

A situação acima destacada (desconfiança) pode ser observada quando for analisada a expectativa de $\mathrm{R} \$ 335$ bilhões até $2025^{37}$. A plataforma Uber reportou perda em $\mathrm{R} \$ 3$ bilhões neste período ${ }^{38}$, que impôs a redução a redução da força de trabalho. Por dita situação, foi proposto e concedido aos chamados "profissionais do futuro" o auxílio-emergencial, caso fosse cumprido as regras previstas na Lei $n^{\circ} 13.982 / 2020^{39}$.

Quanto a disposição de compartilhamento de bens, preliminarmente será necessário a "união de forças" da sociedade em si, para que mesmo com a crise, seja possível o crescimento

\footnotetext{
${ }^{35}$ POLLO, Luiza. Com a pandemia de Covid-19, o que será da economia compartilhada?. UOL, [s. 1], 15 maio. 2020. Disponível em: <https://tab.uol.com.br/noticias/redacao/2020/05/15/com-a-pandemia-de-covid-19-o-quesera-da-economiacompartilhada.htm?fbclid=IwAR2V1eb2sTm0R1Mec_yhXlcpnpuSX4Uz2HbyuqLWW58o3_LRir3EYerP9M>. Acesso em: 09 jun. 2020.

${ }^{36}$ Ibid.

${ }^{37}$ Plataformas de 'economia compartilhada' enfrentam futuro incerto por pandemia. ISTOÉ, [s . 1], 13 maio. 2020. Disponível em: <https://istoe.com.br/plataformas-de-economia-compartilhada-enfrentam-futuro-incertopor-pandemia/>. Acesso em: 09 jun. 2020.

${ }^{38}$ Ibid.

${ }^{39}$ RIBEIRO, Viviane Lícia; CALCINI, Ricardo. Economia compartilhada e a proteção dos direitos dos trabalhadores em tempos de pandemia. Migalhas, [s. 1 ], 24 abr. 2020. Disponível em: <https://www.migalhas.com.br/depeso/325286/economia-compartilhada-e-a-protecao-dos-direitos-dostrabalhadores-em-tempos-de-pandemia>. Acesso em: 10 jun. 2020.
} 
econômico através deste meio. Pontua-se que posteriormente a pandemia provocada pelo Covid-19, algumas alterações no cotidiano deverão ocorrer, a qual deve-se citar duas: (i) trabalho e (ii) mobilidade.

No primeiro item, devido a aglomeração, será necessário a rotatividade do local de trabalho. Isto é, diminuir a densidade de pessoas no local de trabalho, permitindo que porcentagem desta cumpra os seus deveres laborais da sua própria casa ${ }^{40}$, ainda que haja uma inércia a pequenas empresas quanto a reação efetiva da crise. Diante deste cenário de incertezas, o guiamento do Estado a uma saída a crise seria e será essencial, principalmente a economia compartilhada, que através de ações e capacidade de diálogos com os principais envolvidos ${ }^{41}$, permitirá que empregos e funções que não compactuam com a rotatividade no local de trabalho resistam aos efeitos maléficos causados pelo vírus.

Quanto a mobilidade, certamente com a redução de transeuntes nas ruas das cidades (um dos fatores é a possiblidade de home office acima pontuada) foi diminuída, ou espera-se no mínimo que se tenha ocorrido. Em função disto, transporte público em tese teve a sua utilização diminuída e do mesmo modo o transporte compartilhado.

Após os efeitos causados pela pandemia, como conciliar o desejo de utilizar os bens, sem os possui-los como proprietários? Inicialmente, a resposta é que a sociedade em si, ainda que todas as medidas de saúde e segurança tenham sido devidamente tomadas, carregará consigo a preocupação de contaminação por um período de tempo. Nesta ocasião, poderá ocorrer o aumento de compartilhamento de bicicletas, como tem sido visto na cidade de Nova

\footnotetext{
40 POLLO, Luiza. Com a pandemia de Covid-19, o que será da economia compartilhada?. UOL, [s. 1], 15 maio. 2020. Disponível em: <https://tab.uol.com.br/noticias/redacao/2020/05/15/com-a-pandemia-de-covid-19-o-quesera-da-economiacompartilhada.htm?fbclid=IwAR2V1eb2sTm0R1Mec_yhXlcpnpuSX4Uz2HbyuqLWW58o3_LRir3EYerP9M>. Acesso em: 11 jun. 2020.

${ }^{41}$ AMORIM, Wilson Aparecido Costa de. Mercado de Trabalho no Brasil: Antes, Durante... e Depois?. Informações Fipe, n. 475, p. 07-13, abr. 2020, p. 12. Disponível em: <https://downloads.fipe.org.br/publicacoes/bif/bif475a.pdf>. Acesso em: 12 jun. 2020.
} 
York $^{42}$, que mesmo assim deverá receber cuidados básicos, como por exemplo uma limpeza básica com materiais eficientes contra o vírus antes do uso ${ }^{43}$.

Com a utilização das bicicletas e de outros transportes individuais que o individuo utiliza e o deixa em determinado ponto da cidade, será necessária a concessão de estrutura básica para a suportar o acréscimo a demanda. No primeiro caso, ao eventualmente trocarem os bens móveis compartilhados motorizados (cita-se como exemplo o Uber) por alternativos, as pessoas necessitarão no mínimo de um lugar seguro e adequado para se locomoverem. Este caso já iniciado em algumas cidades ao redor do mundo, poderá e deverá manter após o fim do isolamento social ${ }^{44}$.

Conforme a Word Resources Institute, a utilização de veículos individuais e não motorizados reduzirá a produção de carbono, produzidas pelos frota de veículos, a qual encontra-se os bens compartilhados. Além de reduzir os efeitos maléficos a natureza (atmosfera), a utilização de bicicletas dispostas por aplicativos permitirá a prática de atividades físicas, bem como proporciona a realização de compras no comércio local ${ }^{45}$.

Desta feita, defronte ao cenário caótico e desestabilizador que é vivenciado, o primeiro passo deve ser o dado pelos entes estatais, conforme acima pontuado. Após isto, será necessário observar as reais necessidades pós-pandemia, tanto no ambiente laboral, quanto na mobilidade. Outros bens compartilhados deverão ser minimamente regulados, como por exemplo o aluguel de apartamentos por diárias, para que estes sejam higienizados de forma eficazes e preventiva (isto em razão de mesmo com a vacina, poderá existir pessoas que não foram devidamente medicadas). O compartilhamento destes bens continuará e com o tempo voltará ao habitual uso por parte das pessoas. Contudo, para este momento ocorrer - da normalização das atividades deve-se passar pela transição entre o momento atual ao futuro e em ambos casos será obrigatório

\footnotetext{
42 POLLO, Luiza. Com a pandemia de Covid-19, o que será da economia compartilhada?. UOL, [s. 1], 15 maio. 2020. Disponível em: <https://tab.uol.com.br/noticias/redacao/2020/05/15/com-a-pandemia-de-covid-19-o-quesera-da-economiacompartilhada.htm?fbclid=IwAR2V1eb2sTm0R1Mec_yhXlcpnpuSX4Uz2HbyuqLWW58o3_LRir3EYerP9M>. Acesso em: 09 jun. 2020.

${ }^{43}$ AMÂNCIO, Thiago. Bicicletas compartilhadas livram de ônibus cheio, mas é preciso cuidado. Folha de São Paulo. São Paulo, 02 abr. 2020. Disponível em: < https://www1.folha.uol.com.br/cotidiano/2020/04/bicicletascompartilhadas-livram-de-onibus-cheio-mas-e-preciso-cuidado.shtml>. Acesso em: 10 jun. 2020.

44 SCHWEDHELM, Alejandro et. al. Biking Provides a Critical Lifeline During the Coronavirus Crisis. Word Resources Institute. [s. 1], 17 abr. 2020. Disponível em: <https://www.wri.org/blog/2020/04/coronavirusbiking-critical-in-cities>. Acesso em: 10 jun. 2020.

45 Ibid.
} 
a prevenção e utilização de equipamentos que impeçam a propagação do vírus. O que aparenta ocorrer é que a um certo período de tempo a utilização de bens compartilhados diminuirá e enfrentará complicações, para futuramente novamente se estruturar e proporcionar ao usuário soluções que outrora eram pensadas.

\section{CONSIDERAÇÕES FINAIS}

Ante a problemática, o que se esperou, ainda de modo bastante incipiente, é foi observar a nova estrutura da ressignificação da propriedade clássica no Estado Socioambiental de Direito, possibilitando o cenário contemporâneo do acesso e do compartilhamento. Com a aderência a economia do compartilhamento, impôs-se a criação de diversos aplicativos e sites que tratam e operacionalizam o direito de propriedade, concedendo a estes um novo caráter: o de bens temporários, a seres utilizados e posteriormente colocados à venda, alugados ou trocados com outras pessoas/empresas. Surge a possibilidade de o bem receber mais rotatividade quanto aos seus possuidores e assim que eles tenham um maior acesso aos mesmos, que estariam além seu poder aquisitivo.

O trabalho aborda de forma sistemática que o consumo de forma compartilhada e colaborativa entre os usuários atinge diversos tipos de bens, da qual pode-se listar em categorias: (a) móveis e imóveis; (b) duráveis e não duráveis e (c) materiais e imateriais.

Foi demonstrado que quanto a bem móveis, há uma crescente na opção de veículos que são postos ao compartilhamento (necessário relembrar da utilização de veículos através de seus aluguéis, sem comparecer ao escritório tradicional). Nesta linha de raciocínio foi relatado a utilização de bicicletas alugadas ou fornecidas no capítulo quatro. Se analisado o sistema de carona, existem as empresas BlaBlaCar, Uber, 99 e Cabify.

Menciona-se ainda que com a nova vertente de compartilhamento trabalhado na citada pesquisa, há uma disposição entre as pessoas em compartilharem os seus bens. Os níveis variam a depender do local do globo e da cultura incrementada a uma determinada sociedade. 
Apresentadas a conceituação e especificações dos bens compartilhados, espera-se ter alcançado os objetivos desta pesquisa, quais sejam: (i) a efetivação do direito difuso à propriedade de forma a humanizá-la. Nesta esteira, é promovido a inclusão e pertencimento, pois além de reposicionar a função socioambiental da propriedade no contexto jurídico atual, tanto no direito pátrio como no comparado, localiza e define a multipropriedade como desafio jurídico espacial e temporal tendo em vista a relação jurídica de aproveitamento econômico e ambiental de bens comuns e (ii), na era dos diretos difusos, buscou-se conjugar os verbos analisar, acessar e fruir, invés do ter e adquirir, nas atuais sociedades fluídas e digitais, possibilitando novas experiências multissensoriais e ambientais, além de a interação com outros indivíduos neste processo.

\section{REFERÊNCIAS BIBLIOGRÁFICAS}

AMÂNCIO, Thiago. Bicicletas compartilhadas livram de ônibus cheio, mas é preciso cuidado. Folha de São Paulo. São Paulo, 02 abr. 2020. Disponível em: < https://www1.folha.uol.com.br/cotidiano/2020/04/bicicletas-compartilhadas-livram-deonibus-cheio-mas-e-preciso-cuidado.shtml>. Acesso em: 10 jun. 2020.

AMORIM, Wilson Aparecido Costa de. Mercado de Trabalho no Brasil: Antes, Durante... e Depois?. Informações Fipe, n. 475, p. 07-13, abr. 2020, p. 12. Disponível em: <https://downloads.fipe.org.br/publicacoes/bif/bif475a.pdf>. Acesso em: 12 jun. 2020.

ARONNE, Ricardo. Propriedade e Domínio A Teoria da Autonomia: Titularidades e Direitos Reais nos Fractais do Direito Civil-Constitucional. 2. ed. Porto Alegre: Livraria do Advogado Editora, 2014.

BRASIL. Constituição da República Federativa do Brasil de 1988. Disponível em: http://www.planalto.gov.br/ccivil_03/constituicao/constituicaocompilado.htm Acesso em: 30 . abr. 2020 .

. Lei federal $\mathrm{n}^{\circ} 13.777$ de 20 de dezembro de 2018. Altera as Leis $\mathrm{n}_{-}^{\circ} 10.406$, de 10 de janeiro de 2002 (Código Civil), e 6.015, de 31 de dezembro de 1973 (Lei dos Registros Públicos), para dispor sobre o regime jurídico da multipropriedade e seu registro. Disponível em: <http://www.planalto.gov.br/ccivil_03/_Ato2015-2018/2018/Lei/L13777.htm>. Acesso em: 02. maio. 2020.

DINIZ, Maria Helena. Direito Civil Brasileiro: Direito das Coisas. 17. ed. São Paulo: Saraiva, 2002. 
FELSON, Marcus; SPAETH, Joe. L. Community structure and collaborative consumption: “A Routine Activity Approach”. The American Behavioral Scientist, v. 21, n. 4, p. 614-624, 1978.

GOMES, Daniela Vasconcellos. A noção de propriedade no direito civil contemporâneo. Revista Ciência Jurídica, v. 140, 2008.

GONDINHO, André Osório. Função social da propriedade. In: TEPEDINO, Gustavo (coord.). Problemas de direito civil constitucional. Rio de Janeiro: Renovar, 2000.

GUILHERMINO, Everilda Brandão. A tutela das multititularidades: repensando os limites do direito de propriedade. Rio de Janeiro: Lumen Juris, 2018.

LIMA, Frederico Henrique Viegas de. Aspectos teóricos da multipropriedade no direito brasileiro. Revista dos Tribunais, 658/40.Disponível em: https://bdjur.tjdft.jus.br/xmlui/handle/tjdft/36335. Acesso em: 07. jul. 2019.

MAIA, Roberta Mauro Medina. Resenha à obra a tutela das multititularidades: Repensando os limites do direito de propriedade, de Everilda Brandão Guilhermino. Revista Brasileira Direito Civil, v. 18, p. 245-248, out./dez. 2018, p. 246. Disponível em: $<$ https://heinonline.org/HOL/LandingPage?handle=hein.journals/rvbsdirec $18 \& \operatorname{div}=14 \& \mathrm{id}=\&$ page $=>$. Acesso em: 29 maio. 2020.

MASSARO, Vanessa. Reflexões sobre o jusnaturalismo: jus naturale, Web artigos. [s. 1], 06 set. 2014. Disponível em: <https://www.webartigos.com/artigos/reflexoes-sobre-ojusnaturalismo-jus-naturale/124860/> . Acesso em: 07. jul. 2019.

MAZZILLI, Hugo Nigro. A defesa dos interesses difusos em juízo: meio ambiente, consumidor, patrimônio cultural, patrimônio público e outros interesses, 29. ed. São Paulo: Saraiva, 2016.

OLIVEIRA, Álvaro Borges de; BORDERES, Kenia Bernardes. Propriedade, domínio, titularidade, posse e detenção. Revista Jurídica - CCJ/FURB, v. 13, nº 25, p. 99 - 107, jan./jul. 2009. Disponível em: < https://bu.furb.br/ojs/index.php/juridica/article/view/1601/1072>. Acesso em: 08 jun. 2020.

PAGANI, Elaine Adelina. O direito de propriedade e o direito à moradia: um diálogo comparativo entre o direito de propriedade urbana imóvel e o direito à moradia. Porto Alegre: EDICPUCRS, 2009.

Plataformas de 'economia compartilhada' enfrentam futuro incerto por pandemia. ISTOÉ, [s . 1], 13 maio. 2020. Disponível em: <https://istoe.com.br/plataformas-de-economiacompartilhada-enfrentam-futuro-incerto-por-pandemia/>. Acesso em: 09 jun. 2020.

POLLO, Luiza. Com a pandemia de Covid-19, o que será da economia compartilhada?. UOL, [s. 1], 15 maio. 2020. Disponível em: <https://tab.uol.com.br/noticias/redacao/2020/05/15/coma-pandemia-de-covid-19-o-que-sera-da-economiacompartilhada.htm?fbclid=IwAR2V1eb2sTm0R1 Mec_yhXlcpnpuSX4Uz2HbyuqLWW58o3 _-LRir3EYerP9M>. Acesso em: 09 jun. 2020. 
REALE, Miguel apud SARTORI, Nathália de Almeida. Natureza Jurídica Da Multipropriedade. 61f. Trabalho de Conclusão de Curso. Centro Universitário de Brasília, Brasília, 2017, p. 28. Disponível em: https://repositorio.uniceub.br/jspui/bitstream/235/11950/1/21395372.pdf>. Acesso em: 09 ago. 2019.

Reflexões sobre o jusnaturalismo: jus naturale, 2014. Disponível em: https://www.webartigos.com/artigos/reflexoes-sobre-o-jusnaturalismo-jus-naturale/124860/ . Acesso em: 07. Jul. 2019.

RIBEIRO, Viviane Lícia; CALCINI, Ricardo. Economia compartilhada e a proteção dos direitos dos trabalhadores em tempos de pandemia. Migalhas, [s. 1 ], 24 abr. 2020. Disponível em: <https://www.migalhas.com.br/depeso/325286/economia-compartilhada-e-a-protecaodos-direitos-dos-trabalhadores-em-tempos-de-pandemia>. Acesso em: 10 jun. 2020.

RODOTÁ, Stefano. Il terribile diritto. Studi sulla proprietà privata e i beni comuni. 3. ed. Bologna: Il Mulino, 2013.

ROSENVALD, Nelson. Cinco Conceitos que Ressignificam a Propriedade. Nelson Rosenvald. [s. 1], 04 jun. 2019. Disponível em: < https://www.nelsonrosenvald.info/singlepost/2019/06/04/Cinco-Conceitos-que-Ressignificam-a-Propriedade>. Acesso em: 04 jun. 2020 .

SARAIVA, Bruno de Sousa. Uma análise jurídica da multipropriedade imobiliária. THEMIS: Revista da Esmec, v. 9, 2011, pp. 95-113. Disponível em: < http://revistathemis.tjce.jus.br/index.php/THEMIS/article/view/104>. Acesso em: 01 jun. 2020.

SARLET, Ingo Wolfgang. Dignidade da pessoa humana e direitos fundamentais na Constituição Federal de 1988. 8. ed. Porto Alegre: Livraria do Advogado, 2010.

SARTORI, Nathália de Almeida. Natureza Jurídica Da Multipropriedade. 61f. Trabalho de Conclusão de Curso. Centro Universitário de Brasília, Brasília, 2017, p. 28. Disponível em: < https://repositorio.uniceub.br/jspui/bitstream/235/11950/1/21395372.pdf>. Acesso em: 09 ago. 2019.

SCHWEDHELM, Alejandro et. al. Biking Provides a Critical Lifeline During the Coronavirus Crisis. Word Resources Institute. [s. 1], 17 abr. 2020. Disponível em: <https://www.wri.org/blog/2020/04/coronavirus-biking-critical-in-cities>. Acesso em: 10 jun. 2020.

TEPEDINO, Gustavo apud SARTORI, Nathália de Almeida. Natureza Jurídica Da Multipropriedade. Trabalho de Conclusão de Curso. Centro Universitário de Brasília,

TEPEDINO, Gustavo. Multipropriedade imobiliária. Editora Saraiva, São Paulo: 1993.

VENOSA, Sílvio de Salvo. Direito Civil. Direitos Reais. 4a edição. São Paulo: Atlas S/A, 2004. 
WATANABE, Kazuo. Código Brasileiro de Defesa do Consumidor: Comentado pelos autores do anteprojeto. 9. ed. Rio de Janeiro: Forense, 2007.

Data de Submissão: 02/05/2020

Data de Aceite: 24/08/2020 